\title{
Designs: A Multidisciplinary Open-Access Engineering Journal
}

\author{
Hamid Reza Karimi \\ Department of Mechanical Engineering, Politecnico di Milano, via La Masa 1, 20156 Milan, Italy; \\ hamidreza.karimi@polimi.it
}

Received: 3 February 2017; Accepted: 4 February 2017; Published: 8 February 2017

I am honored to serve as the Editor-in-Chief of the new journal of Designs. On behalf of the editorial board, reviewers and authors of the journal, I am very much looking forward to working with the engineering research community to share their latest research results through this platform.

Due to the importance of open access publication and transparent availability of the research results, Designs, launched with a well-established publisher, is aiming to provide a high-quality forum for the exchange of ideas and findings from academics, researchers, and industrial practitioners across different disciplines to publish their work globally under a fully open-access model. In other words, Designs provides a unifying research framework for a wide range of engineering designs of disciplines and industrial applications, including mechanical engineering, electrical engineering, civil engineering, mechatronics, aerospace engineering, bioengineering, energy engineering, industrial engineering and manufacturing systems.

The journal will publish original research papers, research review papers, short communication, book reviews and special issues organized by qualified scientists in their areas of expertise. All manuscripts submitted for possible publication in the journal will be checked by our highly experienced editorial board members before undergoing a rigorous and rapid peer-review process. Designs encourages researchers to publish the results of their recent theoretical and experimental developments in as much detail as possible so that results can be useful for industries or academic research. Therefore, there is no restriction on the length of an article.

The scope of this multidisciplinary journal includes, without being limited to, mechanical design, mechatronics design, electrical design, electronics design, aerospace design, civil design, vehicles design, bioengineering design, energy systems design, product design, industrial design, design methodology and management. I encourage you to submit your original research results to Designs by following the Instructions for authors available at: http://www.mdpi.com/journal/designs/ instructions. Our intention is to notify the authors of the first decisions on their submission within four weeks after the submission date and this can be recognized as one of our strategies to provide the authors a forum for rapid publications subject to an efficient review process.

Finally, I would like to thank our editorial board members, who I have the pleasure to work with in the journal. Special thanks to the authors for contributing to the success of the journal through their quality submissions and to the reviewers for ensuring the quality of the journal. Once again, we are looking forward to receiving your submissions.

(C) 2017 by the author; licensee MDPI, Basel, Switzerland. This article is an open access article distributed under the terms and conditions of the Creative Commons Attribution (CC BY) license (http:/ / creativecommons.org/licenses/by/4.0/). 